\title{
News Journalists and Postruamatic Stress Disorder: a Review of Literature, 2011-2020
}

\author{
Raymond B. Flannery Jr. ${ }^{1,2,3}$
}

Accepted: 4 April 2021 / Published online: 10 April 2021

(C) The Author(s), under exclusive licence to Springer Science+Business Media, LLC, part of Springer Nature 2021

\begin{abstract}
Research has demonstrated that first responders may develop psychological trauma/ posttraumatic stress disorder (PTSD) in the performance of their duties. Often overlooked in these studies of police, firefighters, and paramedics is an additional group of providers who also respond to these same events: news journalists and photo journalists. Although limited in scope, the research literature from 1980 to 2010 assessed an association between PTSD and some news journalists. The strength of these findings are limited due to serious methodological limitations. The present paper reviewed the journalist/PTSD literature from 2011 to 2020 . There were 4558 subjects in 23 studies, which were world-wide in scope. There were 2633 male reporters (58\%) and 1925 female journalists (42\%). The average age of subjects was 34.37 years and the average length of experience was 10.68 years. Many reported either PTSD, PTSD symptoms, depression, and/or substance use. A detailed methodological critique is presented.
\end{abstract}

Keywords News journalists $\cdot$ Photo journalists $\cdot$ Psychological trauma $\cdot$ Posttraumatic stress disorder · Victims

Every day in many parts of the world, first responder police, firefighters, and paramedics [1-3] respond to a variety of serious critical incidents, including violent crimes and natural disasters. Many of these first responders are vulnerable to the onset of psychological trauma and posttraumatic stress disorder (PTSD) as a result of these types of incidents [1, 2]. Often responding to these same incidents are news journalists, where the critical incidents that are assigned for coverage are both grim and gruesome. What, then, is the impact of these same events on news reporters assigned to the same incidents as first responders? Do they develop PTSD, as appears to be the case for other professional groups also responding to these same critical incidents $[4,5]$ ? In addition, journalists are not only reporting on these critical events that they are both witnessing and recording but they may

Raymond B. Flannery Jr.

raymond_flannery@hms.harvard.edu

1 Harvard Medical School, Boston, MA, USA

2 University of Massachsetts Medical School, Worcester, MA, USA

3 Department of Psychiatry, Cambridge Health Alliance, 1493 Cambridge street, Cambridge, MA 02139, USA 
also find themselves direct victims of the events that they are covering. This includes being assaulted, intimidated, taken hostage, and/or being shot at, events that traumatize others. Does this further increase the risk of onset? Although newsrooms have a culture of competitive mental toughness [6], it seems probable that some journalists would be subject to developing psychological trauma and PTSD in responding to these assigned events.

Previous research literature supports this inference [7]. A multifactorial review of this literature from 1980 to 2010 documented the presence of PTSD, depression, and alcohol use in 19 studies of news journalists [7]. The presence of PTSD ranged from $0 \%$ to $33 \%$ [7]. It was higher among journalists confronted with extraordinary events like war or tsunamis and higher in journalists witnessing injury and death. Exposure yielded no significant outcome. The strength of these findings are limited, however, as there were significant methodological limitations in some studies, including self-reports of being traumatized, convenience sampling, small Ns, and unclear definitions of the types of journalists being assessed.

Since 2010, the news media landscape has seen significant technological changes (e.g., UGCs: user generated content submitted by citizens [8]) and policy and procedural changes due to the 2019 pandemic. It also finds itself in an expanded multimedia landscape that has increased competition with a growing number of competing news outlets, more selfemployed journalists, and an expanded social media presence, including citizen critics. The purpose of the present study is to review the journalist/PTSD literature from 2011 to 2020 to assess for the possible PTSD impacts and to evaluate the methodologies utilized in these more recent studies. It was hypothesized that some journalists would report PTSD and/or PTSD symptoms.

\section{Method}

\section{Search Procedure}

The studies to be reviewed were those of unselected news populations where critical traumatic incidents may have occurred. These studies were obtained by means of literature searches in the databases Dart Research, MEDLINE, Pub Med, and PsychINFO with key words such as "journalists," "news journalists," "photo journalists," "psychological trauma," and "posttraumatic stress disorder." Selected studies needed to present the raw data for the total number of impacted journalists, the types of critical incidents being covered, and basic reporter characteristics, such as age, years of experience, types of assignments, in addition to whatever statistical analyses were performed. Selected papers were scanned for additional possible references. No attempt was made to search for unpublished papers.

\section{Inclusion/Exclusion Criteria}

The papers that were selected were from international institutions and appeared in English in peer-reviewed journals from January 1, 2011-December 31, 2020. Unpublished theses and studies with $N<10$ were excluded. Studies employing the same data deck to examine different variables and papers not freely available in the public domain were similarly excluded. 


\section{Results}

The literature search yielded 23 studies for this 10-year period that met the inclusion criteria. The current study's papers are presented chronologically from the earliest to the most recent publications and may be found in Table 1. Empty cells indicate that no data for those specific variables were reported in that study. Common measures utilized in these studies are abbreviated in the table as follows: Beck Depression Inventory (BDI [9]), Journalist Traumatic Exposure Scale (JTES [10]), Impact of Event Scale-Revised (IES-R [11]), PTSD Checklist-Civilian Version (PCL-C [12]), and the Trauma History Questionnaire (THQ [13]).

There were 4558 journalist participants in these studies. Sample size ranged from 19 to 684 subjects. There were 2633 male reporters (58\%) and 1925 female reporters (42\%). Their mean average age was 34.37 years $(\mathrm{SD}= \pm 12.12)$ with a mean range from 30.8 in the youngest group to 44 years in the most senior group. The mean average years of experience was 10.67 years $(S D= \pm 6.46)$ with a mean range from 5.82 in the least experienced group to 21 years in the most experienced group. Most reporters were print journalists. There was a positive correlation between age and female gender $(\times 2=0.237, p=.05)$ and a negative correlation between years of experience and female gender $(\times 2=-0.178, \mathrm{p}=.05)$.

Three studies provided estimates of self-assessed PTSD that ranged from $6 \%$ to $12 \%$. The remaining studies reported the self-assessed presence PTSD symptoms of varying severity and frequency from mild to severe. The presence of depression was noted in 8 studies and the presence of substance use was noted in 6 papers. The presence of psychological trauma and PTSD symptoms were assessed by the IES-R in 13 studies and by the PCL-C in 7 papers. In this review there were 6 European studies, 5 international studies, 4 each in the Middle East and the United States, as well as single papers from Asia, Canada, Mexico, and South Africa.

\section{Discussion}

The results of this review confirm its hypothesis that news journalists would report the onset of PTSD in the course of their news reporting duties. Three studies provided estimates of probable PTSD of 6\% [14], 12\% [16], and 8\% [31] with $8 \%$ and $12 \%$ being greater than the lifetime prevalence in the general population [8]. Each of remaining studies reported PTSD symptoms of varying intensity. These findings are worldwide in scope and suggest that PTSD is a common finding in news journalists. Journalists appear similar to coroners [4] and trauma surgeons [5] in their vulnerability to the onset of psychological trauma/PTSD, when responding to the same types of critical incidents to which first responders are summoned. The data does not permit an assessment of journalists being at increased risk due to personal threats and there is not enough data to adequately assess PTSD risk in non-print journalists.

Subjects in this review also reported depression and substance use, as was reported in the first review [7]. There were more female reporters in this review (42\%) than in the first review (45\%) [7], which noted that the reporters were mostly male (55\%). In this current review female journalists were somewhat older and had less experience. The current study's findings may be an artifact of sampling but it may also indicate more women are entering this field and developing careers. There was no comparable data in the first review 


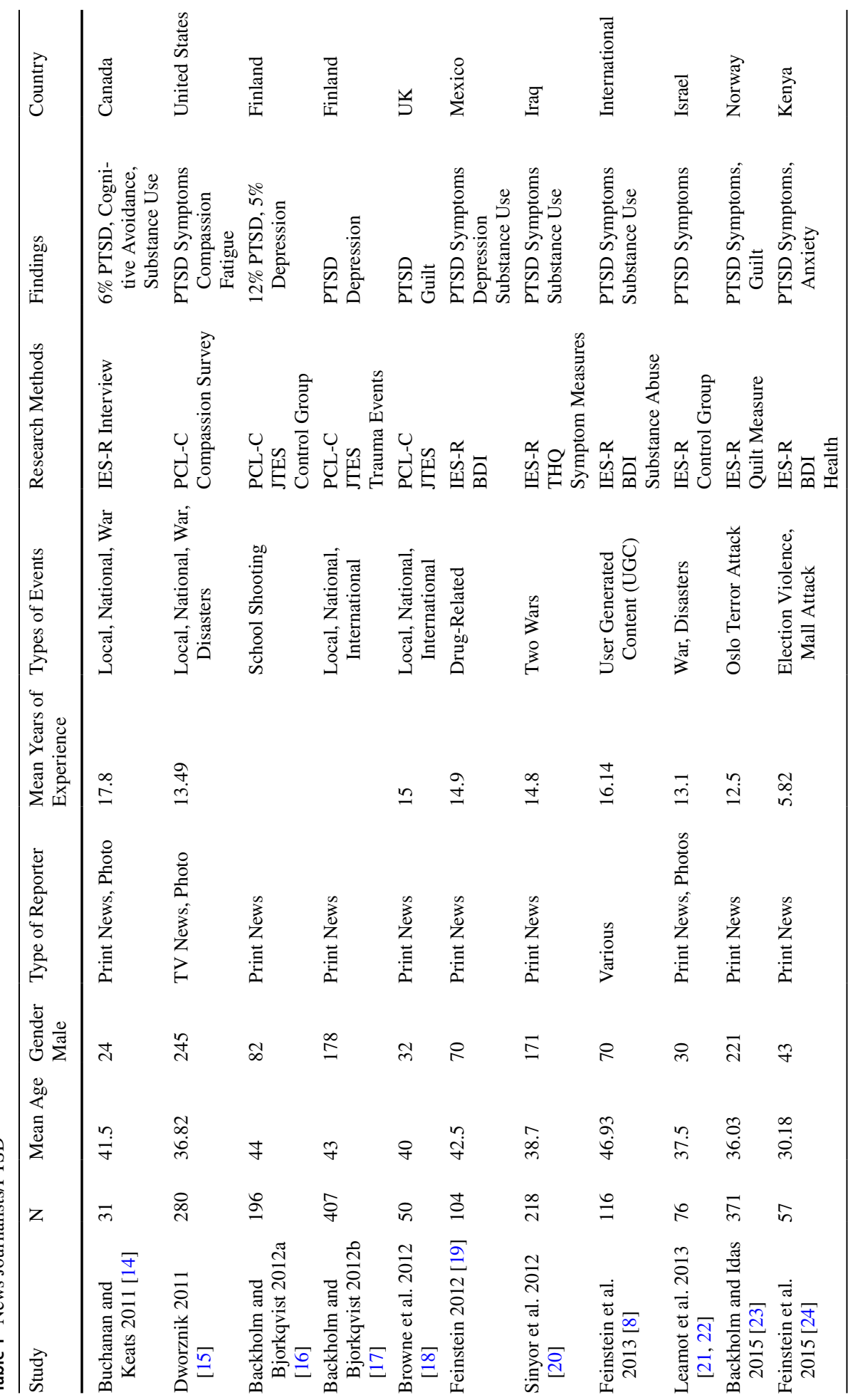




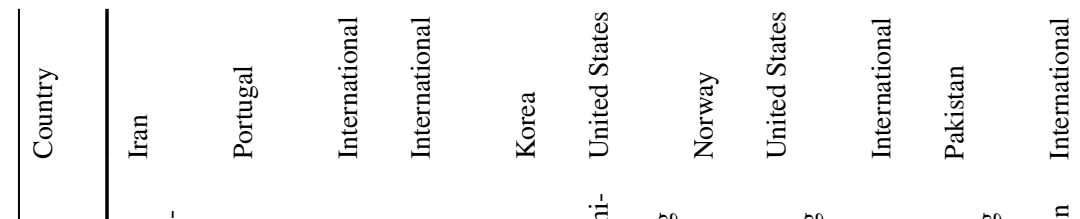

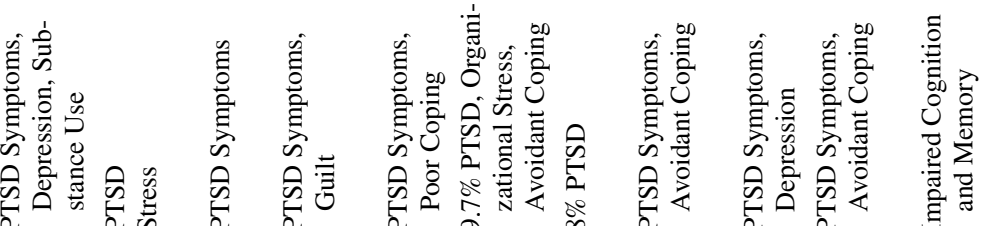

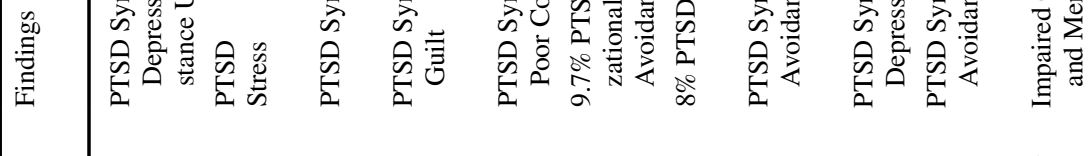

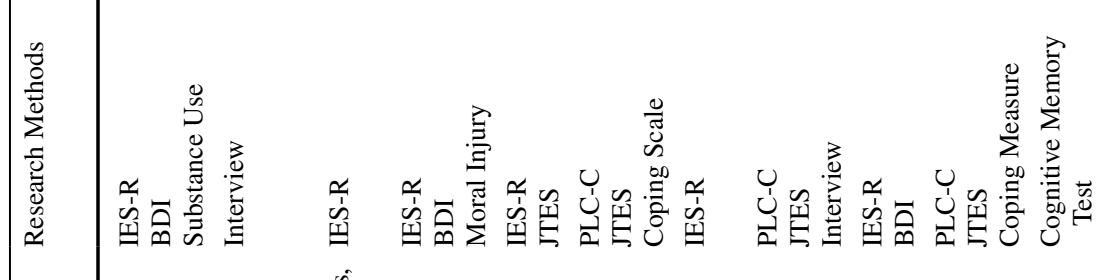

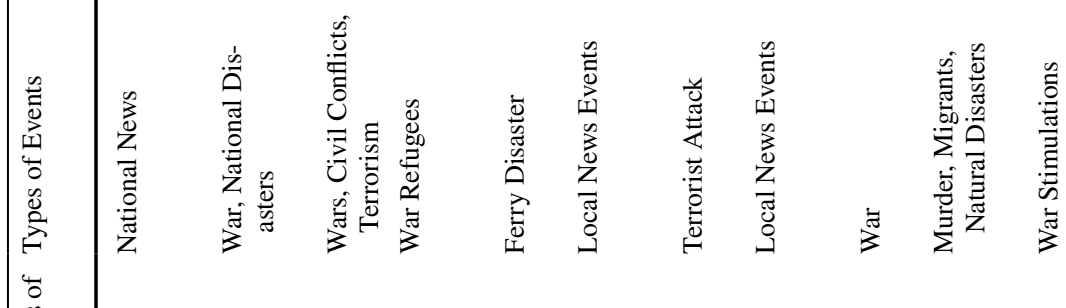

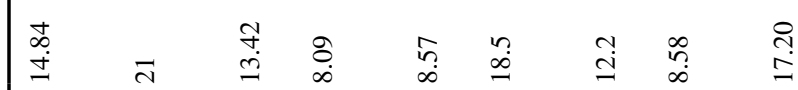

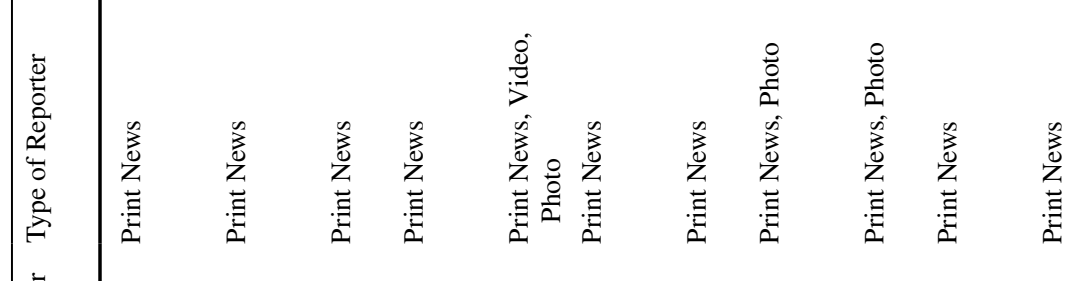

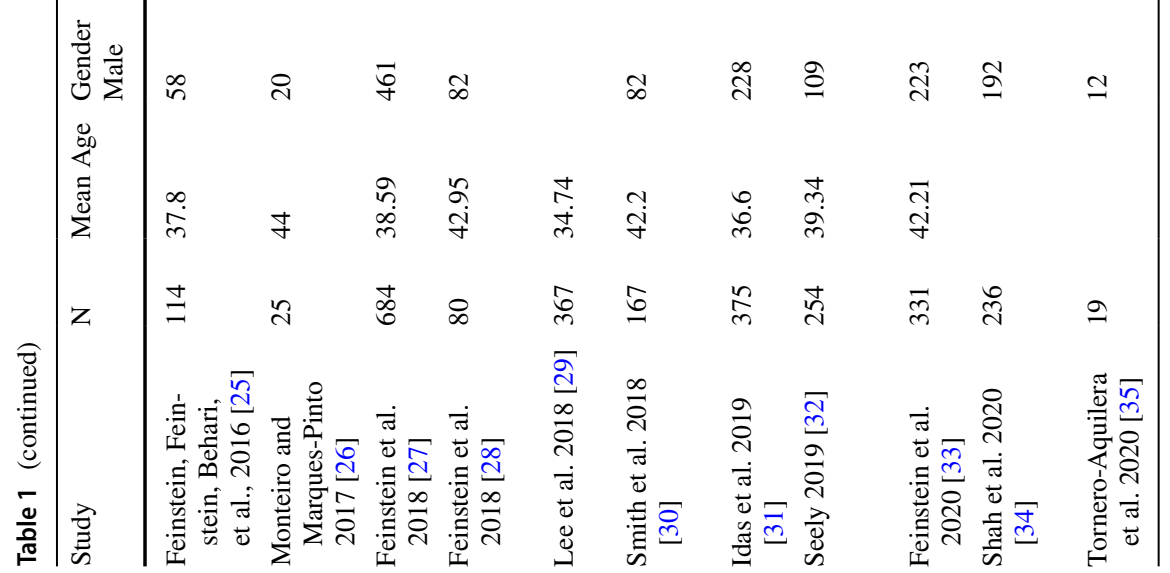


[7] to assess career length. Finally, this review also documents an expanded interest in this topic. In the first 30-year review [7] there were 6.3 papers per decade, whereas in the present review of the current decade there were 23 studies.

The present studies yielded a wide range of methodologies and approaches with significant limitations, so that generalizations of findings across studies cannot be accurately assessed. However, there were subsets of studies had common methodological approaches that permit some limited comparisons. Three studies employed quasi- or semi-structured interviews $[14,16,26]$. These interviews covered a range of topics, such as general stress, news organizational policies, and self-reported symptoms of PTSD. While it is reasonable to assume that some of the subjects in these studies had PTSD, to date, this fact has not been empirically established. Every study in this review relied on self-assessed report data for PTSD and no study utilized a semi-structured psychiatric interview by a clinician to confirm a diagnosis of psychological trauma/PTSD. A second subset of four studies included some form of a control group [16, 19, 21, 22, 32]. For example, one used data from a previously published study; another used journalists as control subjects who were in different parts of the country away from the critical incident being assessed. Control group subjects did not appear to be matched with experimental subjects on basic demographic and work assignment variables in any study.

Many studies assessed depression and substance abuse, two conditions commonly associated with psychological trauma [36]. Depression was evaluated in several papers [8, 17, 20]. [21, 22, 24, 25, 28, 32]. Most studies utilized the BDI [9] and reported a range of disruptions from none too severe. Other papers evaluated substance use $[8,14$, $19,21,22,25,32]$. Here the instruments varied substantially in format from short checklist to self-reports with very limited or no data on validity and reliability being reported. Only one study mentioned the assessment of other forms of substance abuse [9]. Finally, four papers examined the role of guilt [18, 23, 28, 32] and found that guilt emerged over doing tasks inconsistent with personal values, with uncertainty of the rules of conduct, and when not assisting victims. In these studies, guilt, not exposure length, had the more powerful impact.

Methodological Critique Establishing the presence of PTSD in news journalists is a complicated tasks requiring experimental control of multiple variables. However, the present studies in the current review contain several of the limitations also noted in the first review [7]: unclear criteria of subjects, self-reported impairments, and small Ns.

Subjects Since all of the studies relied on self-reports of psychological trauma/PTSD, subjects should be provided with clear operational definitions of psychological trauma/ PTSD for self-assessment. This information should note that PTSD begins 30 days after the critical incident, unless there has been prior exposure in the subject's life that has resulted in PTSD. Studies need to include basic demographic variables, including years of reporting. Subject's type of news assignments should be clear: local/national, war correspondent, print, photo, television, user generated film reporter. The types, frequency, and severity of any past potentially traumatizing event(s) in the correspondent's personal and/or work life need to be documented before fielding the study. Personal victimization is difficult to assess, as journalists' victims are often reluctant to report these painful events due to not recognizing that they have PTSD, stigma, not being believed, newsroom stoicism, and/or fear of being fired. The JTES [10] and the THQ [11] may be of assistance. At a minimum, it would be helpful in analyzing 
results, if subjects were to at least acknowledge the presence or absence of possible traumatic events.

Studies would also benefit from short measures of personal control and social supports, both demonstrated in the literature to potentially mitigate vulnerability to traumatic events [36]. Studies would further benefit from assessments of ongoing organizational stress during the experimental period. Studies need to be clear about the exact date of the critical incident and the elapsed time before the study's subjects arrived onsite.

Measures Studies to date have relied largely on self-report measures and some have altered item content and cutoff points. These instruments need to be culturally relevant and administered as directed to ensure validity and reliability. The most frequently employed self-report measure of psychological trauma/PTSD was the IES-R [11] but it does not reflect the current full spectrum of PTSD [37]. As noted earlier, all self-report measures of psychological trauma/PTSD need to include a semi-structured psychiatric diagnosis, preferable administered by a clinician, to confirm the validity of a self-diagnosis of a traumatic condition resulting in impairment.

Design The studies to date have been retrospective or cross-sectional in design and there remains the need for a longitudinal, prospective study. It should have clear operational definitions of psychological trauma, a reliable and validated measure of psychological trauma, and a semi-structured psychiatric interview to validate self-reports. Studies need to include adequate control groups in which control subjects are matched with experimental subjects on basic demographic variables and potential past trauma histories and are followed and assessed during the same experimental intervention period as the experimental subjects.

Treatments There are several treatment interventions that are available to news journalists seeking care. These include medications for anxiety, depression, and flashbacks; traditional psychotherapy and cognitive behavior therapy [38]; basic health care practices; and newsroom policies that reduce stress on employees. One final approach could be the provision of short-term crisis intervention services that are provided at the time of the critical incident to reduce stress and prevent the onset of PTSD [38, 39]. It is important that future research on this topic continue to refine the role psychological trauma/PTSD in news journalists, as recent research [35] has demonstrated possible alterations in cognition and memory in addition to psychological distress in untreated cases of PTSD in journalists.

\section{Declarations}

This is a review of the literature article only.

Informed Consent There were no human subjects and therefore no need for an IRB review, nor informed consent, nor committee involvement, and no need to obtain consent to publish. Similarly, there were no animals involved in this review with no need to discuss and present a statement and review of animal welfare in this project.

Conflict of Interest The author has no conflicts of interest. 


\section{References}

1. Flannery RB Jr. The violent person: professional risk management strategies for safety and care. New York: American Mental Health Foundation; 2009.

2. Flannery RB Jr. Treating psychological trauma in first responders: a multi-modal paradigm. Psychiatry Q. 2015;86:261-7.

3. Wilson LC. A systematic review of probable posttraumatic stress disorder in first responders following man-made mass violence. Psychiatry Res. 2015;229:21-6.

4. Flannery RB Jr, Greenhalgh T. Coroners and PTSD: treatment implications. Psychiatry Q. 2018;89:765-70.

5. Flannery RB Jr. Psychological trauma and trauma surgeons. Psychiatry Q. 2020; in press.

6. Kovach B, Rosensteil T. The elements of journalism. 2nd ed. New York: Three Rivers Press; 2007.

7. Aoki Y, Malcom E, Yamaguchi S, et al. Mental illness among journalists: a systematic review. Int J Soc Psychiat. 2012;54:377-90.

8. Feinstein A, Audet B, Waknine E. Witnessing images of extreme violence: a psychological study of journalists in the newsroom. J Royal Soc Med Open. https://doi.org/10.1177/0254270414533323.

9. Beck AT, Beck RW. Screening depressed patients in family practice: a rapid technic. Postgrad Med. 1972;52:81-5.

10. Pyevick CM, Newman E, Daleiden E. The relationship among cognitive schemas, job-related traumatic exposure, and posttraumatic stress disorder in journalists. J Traum Stress. 2003;16:325-8.

11. Weiss D, Marmar C. The impact of event scale-revised. In: Wilson JP, Keane TM, editors. Assessing psychological trauma and PTSD. New York: Guilford Press; 1997.

12. Weathers FW, Litz BT, Herman DS, et al. PTSD Checklist (PCL): reliability, validity, and diagnostic utility. Paper presented at the Annual Meeting of the International Society for Traumatic Stress Studies, San Antonio, 1993.

13. Green BL Trauma history questionnaire. In Stamm, BH (Ed.): Measurement of stress, trauma and adaptation (pp. 336-368), 1996.

14. Buchanan M, Keats P. Coping with traumatic stress in journalism: a critical ethnographic study. Int $\mathbf{J}$ Psych. 2011;42:2127-235.

15. Dworznik G. Factors contributing to PTSD and compassion fatigue in television news workers. Int $\mathbf{J}$ Business, Human, and Tech. 2011;1:22-32.

16. Backholm K, Bjorkqvist K. Journalists' emotional reactions after working with the Jokela school shooting incident. Media, War, \& Conflict. 2012a;5:175-90.

17. Backholm K, Bjorkqvist K. The mediating effect of depression between exposure to potentially traumatic events and PTSD in news journalists. European J Psychotraum. 2012b;3:18388. https://doi.org/ 10.3402/ejpt.v3i0.18388.

18. Browne T, Evangeli M, Greenberg N. Trauma-related and posttraumatic stress among journalists. J Trauma Stress. 2012;25:207-10.

19. Feinstein A. Mexican journalists: an investigation of their emotional health. J Trauma Stress. 2012;25:480-3.

20. Sinyor M, Feinstein A. War, journalism, and psychopathology: does gender play a role? Traumatology. 2012;8:29-36.

21. Leavot Y, Sinyor M, Feinstein A. Trauma and psychological distress observed in journalists: a comparison of Israeli journalists and their Western counterparts. Isr J Psychiatry Related Sci. 2013;50:118-21.

22. Feinstein A, Wanga J, Owen J. The psychological effects of reporting extreme violence: a study of Kenyan journalists. J Royal Soc Med Open. 2015;6:1-9.

23. Backholm K, Idas T. Ethical dilemmas, work-related guilt, and posttraumatic stress reactions in news journalists covering the terror attack in Norway in 2011. J Traumatic Stress. 2015;28:142-8.

24. Feinstein A, Wanga J, Owen J. The psychological effects of reporting extreme violence: a study of Kenyan journalists. J Royal Soc Med Open. 2015;6:1-9.

25. Feinstein A, Feinstein S, Behari M, et al. The psychological well-being of Iranian journalists: a descriptive study. J Royal Soc Med. 2016;7:1-5.

26. Monteiro S, Marques-Pinto A. Journalists' occupational stress: a comparative study between reporting critical events and domestic news. Span J of Psychol. 2017;20:e34,1-17.

27. Feinstein A, Osmann J, Patel V. Symptoms of PTSD in frontline journalists: a retrospective examination of 18 years of war and conflict. Can J Psychiatr. 2018;63:629-35.

28. Feinstein A, Pavisian B, Storm H. Journalists covering the refugee and migration crisis are affected by moral injury, not PTSD. J Royal Soc Med. 2018;9:1-7.

29. Lee M, Ha EH, Pae JK. The exposure to traumatic events and symptoms of posttraumatic stress disorder among Korean journalists. Journalism. 2018;19:1308-25. 
30. Smith RJ, Drevo S, Newman E. Covering traumatic news stories: factors associated with posttraumatic stress disorder among journalists. Stress Health. 2018;34:218-26.

31. Idas T, Backholm K, Korhonen J. Trauma in the newsroom: social support, post-traumatic stress and post-traumatic growth among journalists working with terror. Eup J Psychotrauma. 2019;10:1620085. https://doi.org/10.1080/20008198.2019.1620085.

32. Seely N. Journalists and mental health. Newspaper Res J. 2019;40:239-59.

33. Feinstein A, Osman J. Symptoms of posttraumatic stress disorder in journalists covering was and conflict: a study comparing photographers with print reporters. Traumatology. 2020;26:35-9.

34. Shah AS, Jan F, Ginossar T, et al. Trauma exposure and post-traumatic stress disorder among regional journalists in Pakistan. Journalism 2020; https://doi.org/10.11771/1464884920965783.

35. Tornero-Aguilera JF, Robles-Perez JJ, Clemente-Suarez VJ. Could combat stress affect journalists' news reporting? A physiological inquiry. Appl Psychophysiol Biofeedback. 2020;45:231-23.

36. Flannery RB Jr. Posttraumatic stress disorder: the victim's guide to healing and recovery. 2nd ed. New York: American Mental Health Foundation; 2012.

37. American Psychiatric Association. The diagnostic and statistical manual of mental disorders (DSM-5). 5th ed. Washington, DC: American Psychiatric Association Press; 2013.

38. Flannery RB Jr. The assaulted staff action program: coping with the psychological aftermath of violence. New York: American Mental Health Foundation; 2012.

39. Flannery RB Jr. The assaulted staff action program: thirty-year program analysis. Psychiatry Q. 2020. https://doi.org/10.1007/s11126-020-09785.

Publisher's Note Springer Nature remains neutral with regard to jurisdictional claims in published maps and institutional affiliations.

Raymond B. Flannery, Jr., Ph.D., FACLP, designed and directs the Assaulted Staff Action Program (ASAP). Dr. Flannery is Associate Professor of Psychology (Part-Time), Department of Psychiatry, Harvard Medical School, Boston, MA and Adjunct Assistant Professor of Psychiatry, Department of Psychiatry, The University of Massachusetts Medical School, Worcester, MA. 